\title{
Efficacy and Safety of Slowly Infused Propofol Sedation in Pediatric Oncology Procedures
}

Kosuke Akiyama, Shohei Yamamoto*, Mayumi Hayashi, Daisuke Toyama and Keiichi Isoyama

Department of Pediatrics, Showa University Fujigaoka Hospital, Japan

*Corresponding author: Shohei Yamamoto, Department of Pediatrics, Showa University Fujigaoka Hospital, 1-30, Fujigaoka Aoba-ku Yokohama, 227-8501, Japan, Tel: +81459711151; Fax: +8145972 7601; E mail: shohei-y@med.showa-u.ac.jp

Receiving date: October 06 2015; Accepted date: October 25 2015; Published date: October 272015

Copyright: ( 2015 Akiyama K, et al. This is an open-access article distributed under the terms of the Creative Commons Attribution License, which permits unrestricted use, distribution, and reproduction in any medium, provided the original author and source are credited.

\begin{abstract}
Children with hematological malignancies frequently undergo invasive procedures such as bone marrow aspiration and lumbar punctures. Although various methods of sedation are currently used for these procedures, no standard has been established to date. midazolam and ketamine (midazolam/ketamine) have been used for procedural sedation in our department. Since both of these drugs have a long half-life, sedation may persist for an excessively long time after the procedure has been completed. Propofol is an intravenously administered anesthetic that is characterized by the easy control of the depth of anesthesia and rapid recovery. Although side effects such as hypoxia and hypotension have been associated with sedation by propofol, their severities may be reduced using slow infusions. Therefore, we herein used slowly infused propofol $(0.5 \mathrm{mg} / \mathrm{kg}$ over 20 seconds) for these procedures and retrospectively compared its effects with those of midazolam/ketamine. Recovery time was significantly shorter in the propofol group. Although the frequency of side effects such as hypotension was significantly higher in the propofol group, severe side effects were not observed. This may have been because propofol was slowly infused.
\end{abstract}

Although the sample size is too small, the results of the present study suggest that slowly infused propofol might be effective and safe for invasive procedures on pediatric patients. A prospective study is required to further investigate appropriate methods of sedation.

Keywords: Propofol; Midazolam; Ketamine; Procedural sedation; Childhood invasive procedures

\section{Introduction}

Invasive procedures such as bone marrow aspiration and lumbar puncture are essential components for pediatric hematology and oncology patients. Pediatric patients who undergo invasive procedures often require sedation to prevent excessive motion, pain, and anxiety. Although several pharmacological agents have been used for these procedures, a standard has not yet been established. Ideal pharmacological agents have a rapid-onset of action, easily adjustable level of sedation, maintain cardiorespiratory function, and a short duration of activity once their administration is discontinued. Midazolam and ketamine (midazolam/ketamine) have traditionally been used for childhood invasive procedures in our hospital. Although midazolam and ketamine effectively achieve the desired sedation levels for childhood invasive procedures, both of those drugs have a long half-life such that sedation may persist for an excessively long time after the procedure has been completed [1].

Propofol is an intravenously administered anesthetic, and its rapid onset, titratable level of effect, and rapid recovery account for its migration outside the operating room to various sedation venues, including radiology, intensive care, and specific sedation units [2-6]. Although propofol appears to be an ideal pharmacological agent for these procedures, side effects such as hypoxia and hypotension have been associated with propofol sedation [1,2,7]. Previous studies also attributed the occurrence of severe side effects to the rapid infusion of propofol $[1,2]$.
Therefore, we herein used slowly infused propofol for childhood invasive procedures and retrospectively assessed the efficacy and safety profile of slowly infused propofol in those procedures.

\section{Material and Methods}

The aim of this study was to determine the efficacy and safety of slowly infused propofol in childhood invasive procedures.

Forty invasive procedures were performed using midazolam/ ketamine between January and June 2009 while another 40 invasive procedures were performed using propofol between July and December 2009. Thirty-two patients were enrolled into this retrospective study. Approval for this single-center, retrospective cohort study was obtained from the Investigational Review Board of Showa University Fujigaoka Hospital. Written informed consent was obtained from the parents of patients before the procedure. Sedation procedures were performed by pediatric oncologists well trained in advanced life support. Every pediatric oncologist had performed at least 100 pediatric sedations. The second oncologist performed procedures. Patients underwent a medical evaluation before the initiation of sedation. All patients were continuously monitored and had an intravenous line (central venous line) in place with a saline infusion for the duration of sedation and recovery. Systolic and diastolic blood pressure (BP) and oxygen saturation were recorded in all patients 5 minutes before the initiation of sedation and every 5 minutes after the administration of midazolam/ketamine or propofol until the completion of the procedure. These parameters were then recorded every 15 minutes until patients regained consciousness. Children were excluded from this study when no attempt at sedation 
Citation: Kosuke Akiyama, Shohei Yamamoto, Mayumi Hayashi, Daisuke Toyama and Keiichi Isoyama (2015) Efficacy and Safety of Slowly Infused Propofol Sedation in Pediatric Oncology Procedures . J Gen Practice 3: 202. doi:10.4172/2329-9126.1000202

Page 2 of 4

was made because of acute illness or a condition that required the special skills of an anesthesiologist.

The induction time was defined as the time from the administration of the first dose of midazolam/ketamine or propofol to when the patient was unresponsive to verbal or tactile stimuli. The recovery time was defined as the time from the administration of the last dose of midazolam/ketamine or propofol to when the patient had spontaneous eye opening or an appropriate verbal response or crying. The procedure time was defined as the time from the administration of the first dose of Midazolam/ketamine or propofol to when the procedure had finished.

Information gathered included the induction and recovery times, procedure time, adverse effects (decreased BP and oxygen saturation), repeated administration of Midazolam/ketamine or propofol, and the need for therapeutic interventions. The lowest saturation observed during the sedation intervention was recorded, and desaturation was defined as $<90 \%$. The lowest systolic BP during the sedation intervention was recorded. Hypotension was defined as a decrease in systolic BP of $>25 \mathrm{~mm} \mathrm{Hg}$ from baseline. If baseline systolic BP appeared to be elevated as a result of anxiety or stress, hypotension was defined as systolic BP less than the fifth percentile of normal for that age [8]. Patients whose oxygen saturation was under $90 \%$ received supplemental oxygen.

Midazolam/ketamine sedation was initiated by the administration of midazolam (0.1-0.2 mg/kg intravenously) 1 minute prior to that of ketamine in order to reduce the incidence of nausea and vomiting caused by ketamine [9]. Sedation was continued with ketamine (1.0 $\mathrm{mg} / \mathrm{kg}$ intravenously).

Propofol sedation was initiated by the administration of propofol (2 $\mathrm{mg} / \mathrm{kg})$ slowly intravenously $(0.5 \mathrm{mg} / \mathrm{kg}$ over 20 seconds $)$ using mechanical syringe pump until a necessary depth of sedation was achieved. Standard administration of propofol is $0.5 \mathrm{mg} / \mathrm{kg}$ over 10 seconds. In patients with peripheral intravenous catheters in place, 20 $\mathrm{mg}$ of lidocaine was mixed with the initial $180 \mathrm{mg}$ of propofol in an attempt to decrease local pain that may occur when propofol is injected into a small vein. In both regimens, patients also received $1 \%$ lidocaine as a local anesthetic. Supplemental midazolam $(0.1 \mathrm{mg} / \mathrm{kg})$ and propofol $(2 \mathrm{mg} / \mathrm{kg})$ are commonly used to maintain the patient's lack of movement through the procedure.

Statistical analyses were performed using Prism software (Graph Pad). Data are presented as the mean \pm standard deviation (SD). Significant differences between midazolam/ketamine and propofol were detected using the Student's t-test and Fisher's exact test. A P value $<0.05$ was considered significant.

\section{Results}

Forty midazolam/ketamine and propofol sedations to facilitate childhood oncologic procedures in 32 patients between January and December 2009 were retrospectively evaluated (Table 1).

\begin{tabular}{|l|l|}
\hline Age (median, range) & $6 \mathrm{y}, 5 \mathrm{~m}-16 \mathrm{y}$ \\
\hline Male : Female ratio & $22: 10$ \\
\hline ALL & 16 \\
\hline AML & 4 \\
\hline CML & 1 \\
\hline
\end{tabular}

\begin{tabular}{|l|l|}
\hline MDS & 2 \\
\hline AA & 1 \\
\hline RMS & 1 \\
\hline others & 7 \\
\hline $\begin{array}{l}\text { ALL: acute lymphoblastic leukemia, } \\
\text { AML: acute myeloid leukemia, } \\
\text { CML: chronic myeloid leukemia, } \\
\text { MDS: myelodisplastic syndrome, } \\
\text { AA: aplastic anemia, } \\
\text { RMS: rhabdomyosarcoma }\end{array}$ \\
\hline
\end{tabular}

Table 1: Patient characteristics.

The most common procedures performed were bone marrow aspiration and intrathecal chemotherapy (Table 2).

\begin{tabular}{|l|l|l|l|l|}
\hline & Total & $\begin{array}{l}\text { Propofol } \\
\text { group }\end{array}$ & $\begin{array}{l}\text { Midazolam/Ketamine } \\
\text { group }\end{array}$ & P value \\
\hline BMA & 36 & 21 & 15 & 0.41 \\
\hline IT & 28 & 10 & 18 & 0.19 \\
\hline BMA+IT & 7 & 2 & 5 & 0.28 \\
\hline LP & 3 & 2 & 1 & 0.57 \\
\hline BMA+LP & 3 & 3 & 0 & 0.27 \\
\hline $\begin{array}{l}\text { CVC } \\
\text { removal }\end{array}$ & 3 & 2 & 1 & 0.57 \\
\hline BMA: & & & 1 & \\
\hline
\end{tabular}

BMA: bone marrow aspiration, IT: intrathecal chemotherapy, LP: lumbar puncture, CVC: central venous catheter

Table 2: Procedures perform.

The total dosages of midazolam, ketamine and propofol were 0.17 $\mathrm{mg} / \mathrm{kg}, 1.1 \mathrm{mg} / \mathrm{kg}$, and $5.1 \mathrm{mg} / \mathrm{kg}$, respectively (Table 3 ).

\begin{tabular}{|l|l|l|l|}
\hline Drug & Propofol & Midazolam & Ketamine \\
\hline Induction dose $(\mathrm{mg} / \mathrm{kg})$ & $2.2 \pm 0.6$ & $0.16 \pm 0.07$ & $1.1 \pm 0.24$ \\
\hline Additional dose $(\mathrm{mg} / \mathrm{kg})$ & $3.0 \pm 1.4$ & $0.09 \pm 0.07$ & - \\
\hline Total dose $(\mathrm{mg} / \mathrm{kg})$ & $5.1 \pm 1.4$ & $0.17 \pm 0.07$ & $1.1 \pm 0.24$ \\
\hline Values are mean $\pm \mathrm{SD}$ & & \\
\hline
\end{tabular}

Table 3: Doses of each drug.

Supplemental same drugs were required by $18 \%$ (7 out of 40 ) of the midazolam/ketamine group and 98\% (39 out of 40) of the propofol group to maintain the patient's lack of movement through the procedure. Although induction times in the propofol group were significantly longer than those in the midazolam/ketamine group, no significant differences were observed in procedure times. Recovery times in the propofol group were significantly shorter than those in the midazolam/ketamine group (Table 4). 


\begin{tabular}{|l|l|l|l|}
\hline & Propofol group & $\begin{array}{l}\text { Midazolam/ } \\
\text { Ketamine group }\end{array}$ & P value \\
\hline Induction time (min) & $3.8 \pm 2.4$ & $2.5 \pm 1.6$ & $<0.01$ \\
\hline Procedure time (min) & $24 \pm 7.8$ & $22 \pm 8.2$ & 0.465 \\
\hline Recovery time (min) & $60 \pm 34$ & $122 \pm 69$ & $<0.01$ \\
\hline
\end{tabular}

Values are mean \pm SD

Table 4: Time intervals in Propofol versus Midazolam/Ketamine group.

The occurrence of side effects is presented in Table 5.

\begin{tabular}{|l|l|l|l|}
\hline & Propofol group & $\begin{array}{l}\text { Midazolam/ } \\
\text { Ketamine group }\end{array}$ & P value \\
\hline $\begin{array}{l}\text { Oxygen saturation } \\
<90 \%\end{array}$ & $11 / 40(28 \%)$ & $5 / 40(12.5 \%)$ & 0.09 \\
\hline \multicolumn{2}{|l|}{ Drop systolic BP $>25 \mathrm{mmHg}$} & $4 / 40(10 \%)$ & $<0.01$ \\
\hline $\begin{array}{l}\text { and/or systolic BP< }<\text { th } \\
\text { percentile }\end{array}$ & $14 / 40(35 \%)$ & \\
\hline Pain at injection site & & & \\
\hline
\end{tabular}

Table 5: Side effects in Propofol versus Midazolam/Ketamine Groups.

A decrease in oxygen saturation to $<90 \%$ was observed in $27.5 \%$ (11 out of 40) in the propofol group and $12.5 \%$ (5 out of 40 ) in the midazolam/ketamine group. No significant differences were noted between these 2 groups $(\mathrm{P}=0.09)$. In both groups, patients with a decrease in oxygen saturation recovered spontaneously with the administration of oxygen via a mask. No mechanical ventilation was necessary. The frequency of hypotension was significantly higher in the propofol group than in midazolam/ketamine group (35\% (14 out of 40 ) versus $10 \%$ (4 out of 40), respectively). Periods of hypotension were commonly transient and resolved without therapy. Minor side effects such as pain at the injection site were not noted in the propofol group.

\section{Discussion}

Invasive procedures such as bone marrow aspiration and lumbar puncture are a necessary part of the management of childhood cancer. These procedures require sedation to prevent excessive motion, pain, and anxiety. Propofol has several characteristics such as a rapid-onset of action, easily adjustable sedation level, and short duration of activity $[2,3]$. However, side effects such as hypoxia and hypotension have been associated with propofol sedation $[1,2,7]$.

In the present study, hypoxia and hypotension occurred in $27.5 \%$ and $35 \%$ of patients in the propofol group, respectively. Although the occurrence of hypoxia was consistent with previous findings by Gottschling [1] and Hertzog [2], that of hypotension was less frequent. No patients had pain at the site of injection with propofol sedation, and may have been due to the slow infusion of propofol. Gottschling et al reported that hypoxia occurred in $36 \%$ of procedures with propofol and found a clear correlation between a fast bolus application and the occurrence of desaturation [1]. Therefore, we administered propofol slowly $(0.5 \mathrm{mg} / \mathrm{kg}$ over 20 seconds) to avoid these side effects. No treatment other than the administration of oxygen via a mask was necessary for hypoxia and no intravenous fluid administration was needed for hypotension. These results suggest that the severe side effects of propofol sedation might be prevented by its slow infusion.

Induction times were significantly longer in the propofol group than in the midazolam/ketamine group, and were inconsistent with previous findings [1]. This may have been because propofol was infused slowly. Additional propofol was needed in all cases, except for one (98\%), to maintain the patient's lack of movement through the procedures because propofol has no analgesic effects. However, the procedure times were similar in both groups. Since we also infused additional propofol slowly and used $1 \%$ lodocaine as a local anesthetic in all procedures, the total dosage of propofol was less than that administered in previous studies [1,2]. Hypotension has been identified as a dosage-dependent adverse event of propofol $[10,11]$. These findings are consistent with our results in which the occurrence of hypotension was less frequent than that in previous studies.

The recovery time was significantly shorter in the propofol group than in the midazolam/ketamine group. Our results showed that propofol caused hypoxia and hypotension in accordance with previous findings $[1-4,12,13]$. Therefore, it is essential that propofol be administered by pediatric oncologists who are well trained in advanced life support or anesthetists. Propofol should only be administered in an environment in which appropriate monitoring and resuscitation equipment are available. These side effects must also be considered in patients with cardiovascular instabilities, such as patients with preexisting hypotension or hypovolemia.

\section{Conclusion}

Propofol effectively achieved the desired sedation levels for invasive procedures without severe side effects. Although the sample size is too small, propofol anesthesia might be safe for use in these procedures in an environment in which appropriate monitoring and resuscitation equipment are available. Slowly infused propofol may be useful for preventing severe side effects and the administration of a high dosage. A significant difference was observed in the recovery time. Under the proper conditions, propofol anesthesia delivered by experienced pediatric intensivists or anesthetists represents a reasonable option to facilitate invasive procedures in paediatric oncology patients.

\section{References}

1. Gottschling S, Meyer S, Krenn T, Reinhard H, Lothschuetz D, et al. (2005) Propofol versus midazolam/ketamine for procedural sedation in pediatric oncology. J Pediatr Hematol Oncol 27: 471-476.

2. Hertzog JH, Dalton HJ, Anderson BD, Shad AT, Gootenberg JE, et al. (2000) Prospective evaluation of propofol anesthesia in the pediatric intensive care unit for elective oncology procedures in ambulatory and hospitalized children. Pedatrics 106: 742-747.

3. Cravero JP, Blike GT (2004) Review of pediatric sedation. Anesth Analg 99: 1355-1364.

4. Jayabose S, Levendoglu-Tugal O, Giamelli J, Grodin W, Cohn M, et al. (2005) Intravenous anesthesia with propofol for painful procedures in children with cancer. J Pediatr Hematol Oncol 23: 290-293.

5. Chiaretti A, Benini F, Pierri F, Vecchiato K, Ronfani L, et al. (2014) Safety and efficacy of propofol administrered by pediatricians during procedural sedation in children. Acta Paediatr 103: 182-187.

6. Oh JE, Lee Hj, Lee YH (2013) Propofol versus Midazolam for sedation during esophago gastroduodenoscopy in children. Clin Endosc 46: 368-372.

7. Vespasiano M, Finkelstein M, Kurachek S (2007) Propofol Sedation: Intensivists' Experoence With 7304 Cases in a Children's Hospital. Pedatrics 120: e1411-1417. 
Citation: Kosuke Akiyama, Shohei Yamamoto, Mayumi Hayashi, Daisuke Toyama and Keiichi Isoyama (2015) Efficacy and Safety of Slowly Infused Propofol Sedation in Pediatric Oncology Procedures . J Gen Practice 3: 202. doi:10.4172/2329-9126.1000202

Page 4 of 4

8. McDowall RH, Scher CS, Barst SM (1995) Total intravenous anesthesia for children undergoing brief diagnostic or therapeutic procedures. J Clin Anesth 7: 273-280.

9. Blumenthal S, Epps RP, Heavenrich R, Lauer RM, Lieberman, et al. (1977) Report of the task forece on blood pressure control in children. Pedaitrics 59(suppl):797-820.

10. Wathen JE, Robach MG, Mackenzie T, Bothner (2000) Does midazalam alter the clinical effects of intravenous ketamin sedation in children? A randomized, double-blind, placebo-controlled trial. Ann Emerg Med 35: 239-244.
11. Claeys MA, Gepts E, Gamu F (1988) Haemodynamic changes during anaesthesia induced and maintained with propofol. Br J Anaesth 60: 3-9.

12. Pershad J, Gilmore B (2006) Successful implementation of a radiology sedation service staffed exclusively by pediatric emergency physicians. Pediatrics 117: e413-422.

13. Seigler RS, Avant MG, Gwyn DR, Lynch AL, Golding EM, et al. (2000) A comparison of propofol and ketamine/midazolam for intravenous sedation of children. Pediatr Crit Care Med 2: 20-23. 